ГУМАHИTAPHЫЕ НАУКИ
$====================+$ HUMANITARIAN SCIENCES $====================$

УДК 130.2 (Философия культуры. Системы культуры. Культурологические учения)

ХРОНОТОП - СЕМИОТИКА И БУДУЩЕЕ ГОРОДА

\author{
(C) 2020 Е.Я. Бурлина \\ Бурлина Елена Яковлевна, доктор философских наук, профессор кафедры философии и культурологии. \\ E-mail: e.ya.burlina@samsmu.ru \\ Самарский государственный медицинский университет. \\ Самара, Россия
}

Статья поступила в редакцию 20.10.2020

\begin{abstract}
В данной статье автор стремится показать междисциплинарное взаимодействие семиотики и хронотопии на материале великих городов Возрождения, а также Петербурга и других русских городов. Жанр - «память культуры», как сформулировал М.М. Бахтин. По мнению автора статьи, структурная и пространственно-временная память закреплена не только в художественных произведениях, но и в структуре городов. «Хронотоп» и «хронотопия» - базовые инструменты структурного и семиотического анализа города. В этом сходятся последователи М.М. Бахтина со структуралистами и семиотиками школы Ю.М. Лотмана. Именно Ю.М. Лотман - один из основателей российской семиотики - пришел уже в 1990-е годы к выводу, что новые пространственно-временные модусы развивают горожан. Эта теоретическая концепция легла в основу первой части данной статьи. Во второй части рассматриваются университетские практики семиотики и хронотопии города на лекциях по философии, культурологии, эстетике и других гуманитарных предметах.

Ключевые слова: хронотоп города, семиотика города, Бахтин, Лотман, Флоренция, Петербург.
\end{abstract}

DOI: $10.37313 / 2413-9645-2020-22-74-77-84$

\section{1. Хронотоп - семиотика - город}

В предлагаемой статье мы хотели бы обратить внимание на один из новых междисциплинарных разделов гуманитаристики: город и время; городские хронотопы как важнейшие инструменты изучения города. В поле нашего внимания будут находиться также методические вопросы: трансфер новых гуманитарных концепций в практики вузовского преподавания.

ИСТОРИЯ ВОПРОСА. В самом кратком обзоре нельзя не вспомнить, что в отечественной науке проблема «город и время» стала осмысляться еще в начале XX века. Апологетом этого направления был ученый и легендарный Петербургский экскурсовод Н.П. Анциферов. Его методология и книги используются отечественными и зарубежными исследователями и в XXI веке: «Душа Петербурга», «Пути постижения города как социального организма. Опыт комплексного подхода» и др. Создавая образ Петербурга для массовой послереволюционной аудитории, Н.П. Анциферов и другие ученые его круга опирались на профессиональные понятия «гений места», «архетипы пространства», заданные литературой (Петербург в произведениях А.С. Пушкина, Ф.М. Достоевского и др.).

Напомним также, что с 1984 года в Тартуском университете публиковались ученые записки по «Семиотике города и городской культуре», получившие мировую известность. Первый подобный выпуск был посвящен Петербургу, он включал статьи Ю.М. Лотмана, Д.С. Лихачева и других выдающихся ученых [1-5].

Ниже мы обратимся к этим материалам, проецируя их на самые знаменитые города Европы: Флоренция, «цветок Тосканы», величайший центр эпохи Возрождения; Петербург, великая столица русской культуры XIX века. Почему маститые философы и социологи современности вновь и вновь обращаются к интерпретации этих городов? В чем особенность трактовки хронотопа в городе титанов Возрождения? Наконец, насколько подобные темы культурного трансфера могут быть интересны современным студентам?

Не имея возможности в данной статье развернуть обстоятельный библиографический обзор, укажем лишь на некоторые фундаментальные современные исследования Л.М. Баткина, В.С. Библера, а также на работы известного немецкого философа и социолога Г. Зиммеля [6-9].

В 1970-1980-х годах стало ясно, что рядом с новыми философско-культурологическими исследованиями Возрождения стоит фундаментальный 
труд М.М. Бахтина, написанный еще в середине XX века и посвященный народной культуре и роману Франсуа Рабле [10].

Напомним, что Бахтина критиковали семиотики. По их мнению, он был не столько филологом, сколько философом, создавшим свою картину европейской культуры[11]. Примечательно, что мировое признание получили обе ветви гуманитаристики: как ранее созданные концепции хронотопии, по М.М. Бахтину, так и семиотические методики Тартусской школы.

В той давней, но все еще актуальной полемике замечательно «развел стороны» Н.Д. Тамарченко, коротко и определенно сформулировав предмет дискуссии. Цитируем резюме Н.Д. Тамарченко, посвященное Бахтину: «Не слишком упрощая, можно сказать, что в восприятии многих "Проблемы поэтики Достоевского" написаны о необходимости общения и взаимопонимания, о непродуктивности авторитарного монологизма и плодотворности толерантного диалогизма. А "Творчество Франсуа Рабле" - о противостоянии народа, приверженного к телесным радостям, авторитарной власти, которая порождает агеластов и враждебна телесной, особенно сексуальной, свободе. И не только в эпоху средневековья» [12].

Примечательно, что в декабре 1992 года, в последнем прижизненном интервью Ю.М. Лотмана с философом Л. Моревой, в сущности, было заключено "перемирие". Л. Морева тогда предложила обсудить Петербург в трех модусах: Петербург исторический, Петербург сакральный и Петербург вневременной. Однако Ю.М. Лотман неожиданно не согласился с ее предложением. По мысли одного из основателей российской семиотики, проблема «город и время» состоит в саморазвитии горожан [13-17]. Бессмысленно обсуждать город без горожан. По его словам, «город - не кладовая для хранения ценностей. Мы создаем некую модель, жесткую, которая сама себе равна, и она очень удобна для стилизаций, для исследовательских построений. Но в модели нельзя жить, нельзя жить в кинофильме, нельзя жить ни в одном из наших исследований. Они не для этого созданы» [13-17].

По нашему мнению, подобная позиция поставила точку на противопоставлении философскофилологических концепций культуры, создателем которых является М.М. Бахтин, и семиотических методов анализа, направленных на морфологический анализ тех или иных текстов культуры.

И, наконец, на пороге XXI века оформилось достаточно многолюдное течение, суммирующее семантические, пространственно-временные и массово-экскурсионные модели современных российских городов. Сошлемся на концепции Т.С. Злотниковой, Н.Л. Новиковой и других авторов, измеряющих развитие городов их влиятельностью на идентификацию горожан [18-20].

Таким образом, современные философскокультурологические дискурсы города опираются на хронотоп - модели пространства/времени, проявляющиеся в природных, экономических, национальных основаниях и традициях - через сопоставление разных эпох и пространственновременного устройства города в тот или иной период, повседневность и проекции будущего. Один из культурно-философских лейтмотивов-«выход в город», панорама развития горожан во времени: будь то великие латинские буквы на часах Рима или часовые башни Московского Кремля.

\section{2.Студии гуманистов, мировая торговля и экскурсоведение}

Много лет на занятиях со студентами разных вузов - в классическом и специализированном университете в Самаре, расположенной на Волге, мы представляли слушателям и читателям разные города мира. Несколько раз выходили в свет в Самаре наши книги для учителей и студентов: «Путь длиной в века», «Город - Страна - Планета. Модели гуманизма в художественной культуре» [21, 22]. Они были ориентированы на исчезнувший сегодня школьный предмет «Мировая художественная культура», но не только.

Следуя за методологией Бахтина и Лотмана, Анциферова и Зиммеля, мы стремились воспроизвести дух тех городов, которые создали свое новое пространство и новые возможности для развития горожан, а также принципиально новые институты, порожденные культурой. Для современных студентов любых специальностей, будь то медики или информатики, подобные курсы по «Мировой художественной культуре», привязанные к конкретным городам, всегда были востребованы. Одним из самых притягательных городов, расцветшим на стыке Средневековья и Возрождения, 
несомненно, была Флоренция, ставшая для Возрождения центром, похожим на Афины или Петербург, созданный Петром Великим и Екатериной Великой.

Процитируем по книге выдающегося знатока художественной культуры, профессора А.Ф. Лосева «Эстетика Возрождения»: «Центр гуманизма в течение полувека, Флоренция своим благосостоянием и своим престижем смогла, как очаг света, привлечь к себе все богатство человеческого духа. Будучи местом, куда стекались наиболее драгоценные рукописи и где встречались знаменитейшие эрудиты, она стала, помимо того, художественной мастерской, в которую каждый вносил свой талант» [23].

Флоренция выделялась еще в XII-XIII века среди других городов-коммун: мастерская, банковская столица, лаборатория, которая выковывала идеи, подхваченные другими. Раскаленным воздухом Флоренции дышал Данте. В эпоху Возрождения Флоренция сформировала Микеланджело, здесь прожили долгие годы Леонардо да Винчи, Боттичелли. Во Флоренции родилась опера; здесь в канцелярии-«офисе» герцога Козимо Медичи стены украшались полотнами великих художников, превратившими служебные пространства в первый общедоступный музей Уффици.

В художественной истории города выделяют разные периоды: раннего, зрелого и позднего Возрождения. Самые информированные туристы наших дней поражаются количеству музеев, коллекций, роскошных дворцов и великолепных мраморных скульптур, высящихся прямо на улице.

Узкие улочки. Вечереет. Трехэтажные, высокие и торжественные палаццо, сложенные из коричневато-серого, необработанного камня. Они величественны, как крепостные стены. Уже в XIII веке здесь было около 300 сукнодельчатых мастерских, которые принесли городу благополучие и процветание. Население Флоренции к началу XIII века было невиданно огромным - 90 тысяч; в следующем веке оно выросло в десять раз благодаря привлечению новых городских жителей в мануфактурные производства, благодаря возможностям разбогатеть, занимаясь торговлей. Торговали одеждой, снедью, пряностями, книгами, а главное - атмосферой, необычной городской архитектурой, скульптурами, музеями, театрами.

Толпа движется к центру, к площади. Выплыва- ет изумительный абрис мощного и легкого, облитого лунным светом свода. Огромная и как будто невесомая масса Санта Мария дель Фиоре в сиреневом вечернем воздухе кажется высеченной из белого мрамора и вознесенной в небо. Вокруг очень людно. Кажется, что горожане той старой Флоренции, увлеченные спорами о новых найденных античных скульптурах или рукописях, идут в толпе вместе с нами.

Плывет теплая ночь. Упираются в небо зубцы дворца Синьории - выборного городского совета. Так же, как и много лет назад, члены городского совета скуповато распределяют городской бюджет, зная, что за каждую потраченную лиру должны будут отчитаться. C XII-XIII веков все должности городского управления заполняются в результате демократических выборов. Эти выборы сохранились и в XIV-XV веках, когда установилась власть Медичи. И тогда в высших органах управления участвовало 1428 человек. Пополаны - торговцы и фабриканты, «жирный народ», не отдали своего участия в управлении городом.

В стенах Синьории расчет и обыкновенный здравый смысл должны казаться значительными и несуетными. Перед зданием Синьории стоит знаменитый микеланджеловский Давид, заказанный специально как символ и украшение городской власти. Мощный, одухотворенный, пятиметровый, умно контролирующий свою силу гигант.

Уже в XIX веке в медицинских практиках появилось клиническое понятие «синдром Стендаля», напоминающее о том, как известный французский писатель потерял сознание от объема и разнообразия прекрасных скульптур на улицах Флоренции. «Синдром Стендаля» в той или иной форме переживают многие посетители великого города на реке Арно, сраженные обилием великих созданий человеческого гения.

Однако в художественных текстах или просветительских пояснениях мало кто задается вопросом: что породило невиданное богатство Флоренции? Откуда герцоги города и обыкновенные купцы брали деньги на великолепный каррарский мрамор и его доставку во Флоренцию; на оплату дорогостоящих художников, таких как Рафаэль, которых ждали в королевских дворцах всего мира; на постройку Синьории; на великолепные надгробные скульптуры Микеланджело?

В комментариях к бесчисленным флорентий- 
ским коллекциям, как правило, отсутствуют вопросы об экономике Флоренции и немногих других богатейших городов Европы эпохи Возрождения.

B XIV веке Флоренция стала банковской столицей Европы, соизмеримой с Лондоном, Брюгге или Любеком. Само слово «банк» происходит от итальянского «банка» - скамейка, на которой во Флоренции заключались сделки, кредиты и подписывались векселя. В XIII-XV веках ряд крупных городов Европы был объединен и обеспечен единой банковской системой.

Банковские векселя, выданные во Флоренции, обеспечивали торговые транзиты по морю и по суше. Если во Флоренции банки выдавали векселя, котирующиеся по всей Европе, то первая банковская биржа расположилась в городе Брюгге, куда ежегодно приезжали сотни купцов. Здесь устанавливались цены на основные товары, без которых невозможно было вести единую торговую политику. Транснациональная банковская система Европы, руководимая банкирами Флоренции и Брюгге стала чем-то вроде цифровой революции XXI века.

Подобная оценка экономических и финансовых преобразований в Европе эпохи Возрождения признана повсеместно. Можно ссылаться на многочисленные научные публикации, однако в контексте нашей темы полезнее было бы обратить внимание на массовый жанр - монументальную мировую выставку «Transit Брюгге - Новгород», проходившую в немецком городе Эссене. Движение Европы по названному маршруту трактовалось как одна из важнейших мировых магистралей европейской цивилизации [24]. Торговая магистраль между Брюгге и Новгородом наряду с другими многочисленными магистралями сформировала новые городские центры Европы, а значит, новые ценности, смыслы и новые представления о человеке.

По мнению Филиппа Доленгера, известного исследователя экономики позднего Средневековья и Возрождения, купеческая деятельность велась вдоль большой оси городов - от Новгорода до Брюгге и Лондона. Цитата: «К середине XIII в. ганзейские купцы обладали почти торговой монополией на обоих морях. Их коммерческая деятельность велась вдоль большой оси Новгород - Ревель - Любек - Гамбург - Брюгге - Лондон. В XIV в. они расширили и развили сухопутные торговые пути, связывавшие их с югом Германии и Италией. Кроме того, налаживались морские связи с атлантическими портами Франции, Испании и Португалии» $[25,26]$.

Едва ли не центральное место в ряду новых, мобильных и богатых городов этой эпохи принадлежало банковской столице этого времени, какой, как мы выяснили, был прежде всего город на реке Арно. Флорентийские памятники искусства, соборы и дворцы обеспечивались капиталами. Однако дух города формировали не банки, во всяком случае не только банки, а многочисленные гуманитарные кружки и объединения Studia Humanitatis. Члены этих гуманитарных студий называли себя «гуманистами», вкладывая в это понятие новые гуманитарные смыслы свободы, раскрепощенности и величия человека.

Торговец, банкир или герцог считали недопустимым заниматься только своими хозяйственными делами или службой. Каждый гражданин Флоренции демонстрировал страсть к философии, искусству и другим гуманитарным занятиям, иначе горожане сочли бы его низким и недостойным человеком.

Вот несколько знаменитых флорентийских гуманистов.

Герцог Козимо Медичи, установивший свое единоначалие, но сохранивший привилегии демократической республики, был типичным предпринимателем, проводившим много времени в банке и в конторе. Это не мешало ему покровительствовать искусству, философии, окружать себя учеными и художниками.

Священник Марсилио Фичино был духовным главой кружка поэтов, риторов, юристов и художников. Не странно ли это для священника? Ответим: это - гуманизм Возрождения.

Наследник Козимо, Лоренцо Медичи, славился не только как мудрый правитель, но и как духовный, интеллектуальный вождь. Он - глубокий знаток философии, покровительствует искусствам. Его обожают художники.Знаменитые скульптуры Микеланджело в капелле Медичи, созданные и выставленные после смерти Лоренцо, - знак высокого почтения к этому воину, государю и знатоку искусств.

Сын банкира Джаноццо Манетти сумел в зре- 
лом возрасте благодаря одержимости и трудолюбию достичь блестящего знания языков, философии, ораторского искусства. Когда он в роли посла приехал в Венецию и произнес речь, длившуюся больше часа, то восторг дожей был так велик, что они говорили о готовности отдать за такого человека одну из главных земель.

Художник Боттичелли был хорошо известен и любим во Флоренции. Его мастерскую шутливо и ласково прозвали «мастерской бездельников». Споры и диспуты, обнаруживавшие знание языков, умение держать в памяти сотни текстов, постоянно шли в его доме. Эта «гимнастика ума» была необходима самому художнику, его друзьям, среди которых был и великий Леонардо да Винчи.

Универсализм Леонардо поражал гениальностью результатов, разнообразием интересов, но умением изящно и остроумно излагать свои мысли отличались все посетители мастерской. Похожие споры могли вести переписчик книг, торговец, гранд.

Вот, например, загородная вилла «Рай» с прекрасным домом, садом и фонтанами. Ее владелец - флорентийский богач, ему принадлежали также несколько морских судов, доходные дома и палаццо в городе. Времяпрепровождение на такой вилле можно представить по пересказам русского ученого XIX века А.Н. Веселовского, глубокого знатока Возрождения и автора знаменитой "Виллы Альберти", изданной еще в 1870 г. Общество располагается у фонтана, под тенью сосен, у красивого стола, ломящегося от плодов и вин. Обсуждаются вопросы любви, жизни, каждый стремится перещеголять другого в изысканности речи. Когда дам нет, идут ученые дискуссии и дебаты на тему «Какими честными путями добываются деньги, зачем так преследуется ростовщичество?». Ответы полны цитат из «Политики» Аристотеля, но также шуток и живых наблюдений.

Мы далеки от того, чтобы идеализировать духовную жизнь Флоренции XII-XVI веков: распри гвельфов и гибеллинов, «черных» и «белых» гвельфов продолжались чуть не целое столетие. Оппозиция бедноты, поддержавшей Савонаролу, вылилась в бедствия и насилия. И все же это было время необыкновенного тяготения к светскому общению, одухотворенному образованностью и восторженным почитанием гуманитарного знания. Гуманитарные занятия давали ощущение обновления и подъема. Это был тот пьедестал, на который человек мог вознести себя сам, запасшись трудолюбием и одержимостью к постижению мудрости.

Вот еще одно имя знаменитого гуманиста Флоренции - Пико делла Мирандола, один из талантливейших людей Возрождения. У него родилась прекрасная вселенская идея: объединить всех, кто тяготеет к мудрости и Студиа Хуманитатис. В 1486 году Пикоделла Мирандола, желая создать общеевропейский гуманистический форум-диспут, написал «900 тезисов обо всем, что познаваемо».

По его замыслу, в диспуте должны были принять участие все желающие, весь мир. Он оговаривал даже намерение оплатить проезд живущим далеко.

Теперь обратимся к современным гуманитарным теориям. Можно ли определить глобальный хронотоп эпохи Возрождения? В чем состояли его доминантные смыслы?

Вселенский проект, соединяющий прошлое, настоящее и будущее. Человек как точка пересечения земного и вселенского. Можно продолжать версии этого нового хронотопа - пространственно-временной модели мира. Можно детализировать новую семиотическую систему, выдвинутую Возрождением.

Вывод: новые представления о мировом пространстве-времени и месте человека послужили основанием для всей последующей европейской культуры.

Л.М. Баткин, автор блестящих работ о Возрождении, утверждает, что гуманисты Возрождения были первыми группами светской интеллигенции Европы. Выходцы из разных социальных кругов купцы, нотариусы, торговцы, священники, герцоги, банкиры, художники, они вырабатывали новые идеи светской культуры [27].

Страстное погружение в гуманитарные занятия еще не делало человека «гуманистом» в современном понимании, но позволяло ему реализовать себя полностью, возвыситься, как считали флорентийские гуманисты, достичь полного благородства и достоинства. Как показало время, это был культурный фермент огромной значимости и долговременности.

Подобные процессы, разумеется, происходили и в других городах той же эпохи.

Оглядываясь на культурный потенциал возрожденческого города нельзя не сказать об аналогах в 
России. Разве «Зеленая лампа» была только литературным собранием, а не собранием русских гуманистов? Также «Могучая кучка» и «Товарищество передвижников» объединяли будущих создателей опер и картин, которые формировали новые знаковые системы и новые художественные пространства национальной культуры. Разве уникальные культурные проекты в Куйбышеве- Самаре, включая уже вошедшие в историю "Грушинский фестиваль", Конкурсы Д.Б. Кабалевского, а также совсем новые - Д.Д. Шостакович: 2020; Ширяевское биенале - не способствовали консолидации "человеческого материала" в городе на Волге?...

Таким образом, эпоха Возрождения позволяет не только пристально вглядеться в прекрасное прошлое европейской культуры, наполненное новыми идеями и формами жизни, но и устремиться в культурные проекты будущего: где будут новые центры мировой культурной эпохи, с какими идеями они будут связаны, какими будут будущие гуманисты?..

1. Семиотика города и городской культуры. Петербург // Ученые записки Тартуского госуниверситета. - 1984. -

Вып. 664. - 139 с.

2. Лотман, Ю. М. Символика Петербурга и проблемы семиотики города // Семиотика города и городской культуры. Петербург: Ученые записки Тартуского госуниверситета. - 1984. - Вып. 664. - 139 с. - С. 30.

3. Лихачев, Д. С. Заметки к интеллектуальной топографии Петербурга первой четверти двадцатого века (по воспоминаниям) // Круг чтения: календарь. - М., 1991. - С. 174-175.

4. Санна Турома. Семиотика городского пространства Ю.М. Лотмана: опыт переосмысления // НЛО. - 2009. - № 4 (98). - C. 66-76.

5. Хасиева, М. А. Петербург Достоевского: семиотика городского пространства в контексте развития петербургского текста // Филологические науки. Вопросы теории и практики. - 2017. - №3-3 (69). - С. 45-47.

6. Баткин, Л. М. Итальянские гуманисты: стиль жизни и мышления. - М.: Наука, 1978. - 209 с.

7. Библер, В. С. Галилей и логика мышления Нового времени // Механика и цивилизация XVII-XIX вв. / Под ред. А.

Т. Григоряна и Б. Г. Кузнецова. Сост. В. С. Кирсанов. - М.: Наука, 1979. - С. 449.

8. Неретина, С. А., Огурцов, А. П. Время культуры: Монография. - М., 2000. - 343 с.

9. Зиммель, Г. Рим. Флоренция. Венеция / Пер. с нем. А. Филиппова-Чехова под ред. М. Лепиловой. - M.: Grundrisse, 2014. (Varia. 05). - C. 96.

10. Бахтин, М. М. Творчество Франсуа Рабле и народная культура средневековья и Ренессанса. - М.: Эксмо, 2015. $541 \mathrm{c}$.

11. Гаспаров, М. Л. История литературы как творчество и исследование: случай Бахтина // Русская литература XXXXI веков: проблемы теории и методологии изучения: Матер. Междунар. науч. конф. М., 10-11 ноября 2004. Ред.сост. С.И. Кормилов. - М.: Московск. гос. ун-т им. М.В. Ломоносова, 2004. - С. 8-10.

12. Тамарченко, Н. Д. Актуальность Бахтина (Полемические заметки)// Новый филологический вестник. - 2006. - № 2(3). - C. 179-186.

13. Лотман, Ю. М. Город и время // Петербургские чтения по теории, истории и философии культуры. - СПб., 1993. Вып. 1. - С. 84-92.

14. Город и время: Интернациональный научный альманах Life sciences, тематический выпуск: в 2 т. T. 1 / Самар. гос. мед. ун-т; ред. Е.Я. Бурлина. - Самара: Книга, 2012. - 208 с. - С. 9.

15. Бурлина, Е. Я., Голубинов, Я. А., Иливицкая, Л. Г., Барабошина, Н. В., Кузовенкова, Ю. А., Шилинг, Е. Хронотопия города: монография (с приложением сборника научных статей «Гении места» / Самар. гос. мед. ун-т; науч. рук. Е.Я. Бурлина. - Самара: Книжное издательство, 2016. - 240 с.

16. Город как сцена. История. Повседневность. Будущее: науч. альманах. В 2 т. Т. 1 / Самар. гос. мед. ун-т; Отв. ред. Е.Я. Бурлина; Сост.: Ю.А. Кузовенкова, Л.Г. Иливицкая, Я.А. Голубинов. - Самара: Медиа-Книга, 2015. - 388 с. 17. Бурлина, Е. Я. «Что ни город, то хронотоп». Пространственно-временная диагностика города // Международный научно-исследовательский журнал. - 2017. - № 9-1 (63). - С. 103-108.

18. Злотникова, Т. С. Время старого города // Город и время: Интернациональный научный альманах Life sciences, тематический выпуск: в 2 т. Т. 2 / Самар. гос. мед. ун-т; ред. Е.Я. Бурлина. - Самара: Книга, 2012. - 208 с. - С. 9. 19. Новикова, Н. Л. Идентификация человека в координатах городского пространства// Город и время: Интернациональный научный альманах Life sciences, тематический выпуск: в 2 т. Т. 2 / Самар. гос. мед. ун-т; ред. Е.Я. Бурлина. Самара: Книга, 2012. - 208 с. - С. 34; С. 92. 
20. Ланцевская, Н. Ю. Семиотика пространства провинции как источник развития имиджа места // Фундаментальные исследования. - 2014. - № 5 (часть 2). - С. 423-427.

21. Бурлина, Е. Я. Путь длиной в века: Беседы о преподавании худож. культуры: Кн. для учителя. - М.: Просвещение, 1994. - 173 c.

22. Бурлина, Е. Я. Город - страна - планета. Модели гуманизма в художественной культуре: монография / 5-е изд., доп. и расшир. - Самара: СНЦ РАН, 2014. - 184 с.

23. Лосев, А. Ф. Эстетика Возрождения. - М.: Мысль, 1982. - 623 с. - С. 119, с. 136.

24. Transit Brugge Novgorod: Eine Strasse Durch Die Europaische Geschichte (German Edition) by Ferdinand Seibt. Essen, Katalog 1997.

25. The German Hansa. By Philippe Dollinger. Translated and edited by D.S. Ault and S.H. Steinberg. - London: Macmillan, 1970. S.17.

26. Доллингер, Ф. Ганзейский союз. Торговая империя Средневековья от Лондона и Брюгге до Пскова и Новгорода. М.: Центрполиграф, 2020.

27. Баткин, Л. Итальянское Возрождение в поисках индивидуальности. - М.: Наука, 1989. - 270 с. - С. 9.

\title{
URBAN CHRONOTOPE - URBAN SEMIOTICS. FLORENCE AND SAINT PETERSBURG
}

\author{
(c) 2020 E.Ya. Burlina \\ Elena Ya. Burlina, Doctor of Philosophy, Professor \\ of the Department of Philosophy and culturology. \\ E-mail:e.ya.burlina@samsmu.ru \\ Samara State Medical University. \\ Samara, Russia
}

In this paper author presents an interdisciplinary interaction betweeen semiotics and chronotopy. The paper refers to the great cities of Renaissance and the Russian cities like Saint Petersburg. As M. M. Bakhtin formulated, "genre is cultural memory". According to the author, the structural and spatiotemporal memory lies in the core not only of artistic works, but of urban structurestoo.As an instruments of structural and semiotic analysis of city, the terms of chronotope and chronotopy were coined. The followers of M. M. Bakhtin, the structuralists and the semeiologists of the Yu. M. Lotman Semiotic School now agree on this point.

In 1990s, one of the founders of Russian semiotics, Yu. M. Lotman came to the conclusion that new spatiotemporal modes can crystallize and spiritually develop citizens. This concept formed the basis of the first part of the paper. The second part considers practical opportunities of semiotics and urban chronotopy in dialogue with students during classes on such humanities subjects as philosophy, global art culture, aestetics e.t.c. According to the author, urban chronotope and urban semiotics are different and complementary instruments of scientific comprehension and development of cities.

Keywords: urban chronotope, urban semiotics, Bakhtin, Lotman, Florence, Saint Petersburg.

DOI: $10.37313 / 2413-9645-2020-22-74-77-84$

1. Semiotika goroda i gorodskoy kul'tury. Peterburg (Semiotics of the city and urban culture. Petersburg) // Uchenyye zapiski Tartuskogo gosuniversiteta. - 1984. - Vyp. 664. - 139 s.

2. Lotman, YU. M. Simvolika Peterburga i problemy semiotiki goroda (Symbols of St. Petersburg and the problems of the semiotics of the city) // Semiotika goroda i gorodskoy kul'tury. Peterburg: Uchenyye zapiski Tartuskogo gosuniversiteta. 1984. - Vyp. 664. - 139 s. - C. 30.

3. Likhachev, D. S. Zametki k intellektual'noy topografii Peterburga pervoy chetverti dvadtsatogo veka (po vospominaniyam) (Notes on the intellectual topography of St. Petersburg in the first quarter of the twentieth century (according to memoirs) // Krug chteniya: kalendar'. - M., 1991. - S. 174-175.

4. Sanna Turoma. Semiotika gorodskogo prostranstva YU.M. Lotmana: opyt pereosmysleniya (Semiotics of urban space Yu.M. Lotman: an experience of rethinking) // NLO. - 2009. - № 4 (98). - S. 66-76.

5. Khasiyeva, M. A. Peterburg Dostoyevskogo: semiotika gorodskogo prostranstva v kontekste razvitiya peterburgskogo teksta (Dostoevsky's Petersburg: the semiotics of urban space in the context of the development of the Petersburg text) // Filologicheskiye nauki. Voprosy teorii i praktiki. - 2017. - №3-3 (69). - S. 45-47.

6. Batkin, L. M. Ital'yanskiye gumanisty: stil' zhizni i myshleniya (Italian humanists: lifestyle and thinking). - M.: Nauka, 
Известия Самарского научного иентра Российской академии наук.

Социальные, гуманитарные, медико-биологические науки, m. 22, №74, 2020

Izvestiya of the Samara Science Centre of the Russian Academy of Sciences.

Social, Humanities, Biomedical Sciences, Vol. 22, no. 74, 2020

1978. - $209 \mathrm{~s}$.

7. Bibler, V. S. Galiley i logika myshleniya Novogo vremeni (Galileo and the logic of modern thinking) // Mekhanika i tsivilizatsiya XVII-XIX vv. / Pod red. A. T. Grigoryana i B. G. Kuznetsova. Sost. V. S. Kirsanov. - M.: Nauka, 1979. - S. 449.

8. Neretina, S. A., Ogurtsov, A. P. Vremya kul'tury (Time of culture): Monografiya. - M., 2000. - 343 s.

9. Zimmel', G. Rim. Florentsiya. Venetsiya (Rome. Florence. Venice) / Per. s nem. A. Filippova-Chekhova pod red. M. Lepilovoy. - M.: Grundrisse, 2014. (Varia. 05). - S. 96.

10. Bakhtin, M. M. Tvorchestvo Fransua Rable i narodnaya kul'tura srednevekov'ya i Renessansa (Creativity of Francois Rabelais and the folk culture of the Middle Ages and the Renaissance). - M.: Eksmo, 2015. - $541 \mathrm{~s}$.

11. Gasparov, M. L. Istoriya literatury kak tvorchestvo i issledovaniye: sluchaǐ Bakhtina (History of literature as creativity and research: the case of Bakhtin) // Russkaya literatura XX-XXI vekov: problemy teorii i metodologii izucheniya: Mater. Mezhdunar. nauch. konf. M., 10-11 noyabrya 2004. Red.-sost. S.I. Kormilov. - M.: Moskovsk. gos. un-t im. M.V. Lomonosova, 2004. - S. 8-10.

12. Tamarchenko, N. D. Aktual'nost' Bakhtina (Polemicheskiye zametki) (Bakhtin's relevance (Polemic notes) // Novyy filologicheskiy vestnik. - 2006. - № 2(3). - S. 179-186.

13. Lotman, YU. M. Gorod i vremya (City and time) // Peterburgskiye chteniya po teorii, istorii i filosofii kul'tury. - SPb., 1993. - Vyp. 1. - S. 84-92.

14. Gorod i vremya: Internatsional'nyy nauchnyy al'manakh Life sciences, tematicheskiy vypusk (City and time: International scientific almanac Life sciences, thematic issue): v. 2 t. T. 1 / Samar. gos. med. un-t; red. Ye.YA. Burlina. - Samara: Kniga, 2012. - 208 s. - S. 9.

15. Burlina, Ye. YA., Golubinov, YA. A., Ilivitskaya, L. G., Baraboshina, N. V., Kuzovenkova, YU. A., Shiling, Ye. Khronotopiya goroda: monografiya (s prilozheniyem sbornika nauchnykh statey «Genii mesta» (Chronotopia of the city: a monograph (with a collection of scientific articles "Geniuses of the place") / Samar. gos. med. un-t; nauch. ruk. Ye.YA. Burlina. - Samara: Knizhnoye izdatel'stvo, 2016. - $240 \mathrm{~s}$.

16. Gorod kak stsena. Istoriya. Povsednevnost'. Budushcheye: nauch (The city as a stage. History. Everyday life. Future: scientific. almanac). al'manakh. V 2 t. T. 1 / Samar. gos. med. un-t; Otv. red. Ye.YA. Burlina; Sost.: YU.A. Kuzovenkova, L.G. Ilivitskaya, YA.A. Golubinov. - Samara: Media-Kniga, 2015. - $388 \mathrm{~s}$.

17. Burlina, Ye. YA. «Chto ni gorod, to khronotop». Prostranstvenno-vremennaya diagnostika goroda ("Every city is a chronotope." Spatial-temporal diagnostics of the city) // Mezhdunarodnyy nauchno-issledovatel'skiy zhurnal. - 2017. - № 9-1 (63). - S. 103-108.

18. Zlotnikova, T. S. Vremya starogo goroda (Time of the old city) // Gorod i vremya: Internatsional'nyy nauchnyy al'manakh Life sciences, tematicheskiy vypusk: v 2 t. T. 2 / Samar. gos. med. un-t; red. Ye.YA. Burlina. - Samara: Kniga, 2012. - 208 s. S. 9.

19. Novikova, N. L. Identifikatsiya cheloveka v koordinatakh gorodskogo prostranstva (Human identification in the coordinates of urban space) // Gorod i vremya: Internatsional'nyy nauchnyy al'manakh Life sciences, tematicheskiy vypusk: v $2 \mathrm{t}$. T. 2 / Samar. gos. med. un-t; red. Ye.YA. Burlina. - Samara: Kniga, 2012. - 208 s. - C. 34; S. 92.

20. Lantsevskaya, N. YU. Semiotika prostranstva provintsii kak istochnik razvitiya imidzha mesta (Semiotics of provincial space as a source of development of the image of the place) // Fundamental'nyye issledovaniya. - 2014. - № 5 (chast' 2). - S. 423-427.

21. Burlina, Ye. YA. Put' dlinoy v veka: Besedy o prepodavanii khudozh. kul'tury (A Century-Long Path: Conversations on Teaching Artists. culture): Kn. dlya uchitelya. - M.: Prosveshcheniye, 1994. - 173 s.

22. Burlina, Ye. YA. Gorod - strana - planeta. Modeli gumanizma v khudozhestvennoy kul'ture: monografiya (City - country - planet. Models of humanism in artistic culture: monograph ) / 5 ye izd., dop. i rasshir. - Samara: SNTS RAN, 2014. - 184 s.

23. Losev, A. F. Estetika Vozrozhdeniya (Aesthetics of the Renaissanc). - M.: Mysl', 1982. - 623 s. - S. 119, s. 136.

24. Transit Brugge Novgorod: Eine Strasse Durch Die Europaische Geschichte (German Edition) by Ferdinand Seibt. Essen, Katalog 1997.

25. The German Hansa. By Philippe Dollinger. Translated and edited by D.S. Ault and S.H. Steinberg. - London: Macmillan, 1970. - S.17.

26. Dollinger, F. Ganzeyskiy soyuz. Torgovaya imperiya Srednevekov'ya ot Londona i Bryugge do Pskova i Novgoroda (Hanseatic League. Trade empire of the Middle Ages from London and Bruges to Pskov and Novgorod.). - M.: Tsentrpoligraf, 2020.

27. Batkin, L. Ital'yanskoye Vozrozhdeniye v poiskakh individual'nosti (Italian Renaissance in Search of Individuality). - M.: Nauka, 1989. - 270 s. - S. 9. 